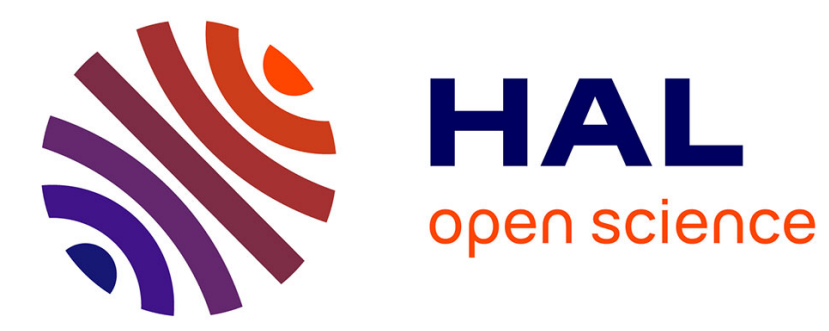

\title{
The reduction of CSFV transmission to untreated pigs by the pestivirus inhibitor BPIP: a proof of concept
}

\author{
R. Vrancken, A. Haegeman, J. Dewulf, J. Paeshuyse, G. Puerstinger, M.
} Tignon, M.-F. Le Potier, J. Neyts, F. Koenen

\section{- To cite this version:}

R. Vrancken, A. Haegeman, J. Dewulf, J. Paeshuyse, G. Puerstinger, et al.. The reduction of CSFV transmission to untreated pigs by the pestivirus inhibitor BPIP: a proof of concept. Veterinary Microbiology, 2009, 139 (3-4), pp.365. 10.1016/j.vetmic.2009.06.026 . hal-00526939

\section{HAL Id: hal-00526939 \\ https://hal.science/hal-00526939}

Submitted on 17 Oct 2010

HAL is a multi-disciplinary open access archive for the deposit and dissemination of scientific research documents, whether they are published or not. The documents may come from teaching and research institutions in France or abroad, or from public or private research centers.
L'archive ouverte pluridisciplinaire HAL, est destinée au dépôt et à la diffusion de documents scientifiques de niveau recherche, publiés ou non, émanant des établissements d'enseignement et de recherche français ou étrangers, des laboratoires publics ou privés. 


\section{Accepted Manuscript}

Title: The reduction of CSFV transmission to untreated pigs by the pestivirus inhibitor BPIP: a proof of concept

Authors: R. Vrancken, A. Haegeman, J. Dewulf, J. Paeshuyse, G. Puerstinger, M. Tignon, M.-F. Le Potier, J. Neyts, F. Koenen

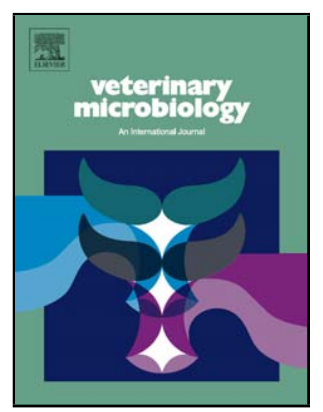

PII: $\quad$ S0378-1135(09)00311-3

DOI: $\quad$ doi:10.1016/j.vetmic.2009.06.026

Reference: $\quad$ VETMIC 4481

To appear in: $\quad$ VETMIC

Received date: $\quad 1-12-2008$

Revised date: $\quad 3-6-2009$

Accepted date: $\quad$ 12-6-2009

Please cite this article as: Vrancken, R., Haegeman, A., Dewulf, J., Paeshuyse, J., Puerstinger, G., Tignon, M., Le Potier, M.-F., Neyts, J., Koenen, F., The reduction of CSFV transmission to untreated pigs by the pestivirus inhibitor BPIP: a proof of concept, Veterinary Microbiology (2008), doi:10.1016/j.vetmic.2009.06.026

This is a PDF file of an unedited manuscript that has been accepted for publication. As a service to our customers we are providing this early version of the manuscript. The manuscript will undergo copyediting, typesetting, and review of the resulting proof before it is published in its final form. Please note that during the production process errors may be discovered which could affect the content, and all legal disclaimers that apply to the journal pertain. 


\section{The reduction of CSFV transmission to untreated pigs by the pestivirus inhibitor}

\section{BPIP: a proof of concept}

R. Vrancken ${ }^{1}$, A. Haegeman ${ }^{1}$, J. Dewulf ${ }^{2}$, J. Paeshuyse $^{3}$, G. Puerstinger ${ }^{4}$, M. Tignon $^{1}$, M.-F. Le Potier ${ }^{5}$, J. Neyts ${ }^{3}$, F. Koenen ${ }^{1}$.

${ }^{1}$ Veterinary and Agrochemical Research Centre, Groeselenberg 99, B-1180 Ukkel, Belgium

${ }^{2}$ Department of Reproduction, Obstetrics and Herd Health, Ghent University, Salisburylaan 133, B-9820 Merelbeke, Belgium

${ }^{3}$ Rega Institute for Medical Research, KU Leuven, Minderbroederstraat 10, B-3000 Leuven, Belgium

${ }^{4}$ Department of Pharmaceutical Chemistry, Institute of Pharmacy, University of Innsbruck, Innrain 52a, A-6020 Innsbruck, Austria

${ }^{5}$ Agence Française de Sécurité Sanitaire des Aliments, Unité de Virologie

Immunologie Porcines, BP53, F-22440 Ploufragan, France

Keywords : Antivirals, pestivirus, classical swine fever virus, virus transmission

* Corresponding author. Mailing address: Veterinary and Agrochemical Research

Centre, Groeselenberg 99, B-1180 Ukkel, Belgium. Phone:+3223790520. Fax:

+3223790666. Email: Rovra@var.fgov.be 


\section{Abstract.}

5-[(4-bromophenyl)methyl]-2-phenyl-5H-imidazo[4,5-c]pyridine $\quad$ (BPIP) is a representative molecule of a novel class of highly active in vitro inhibitors of the replication of Classical swine fever virus (CSFV). We recently demonstrated in a proof of concept study that the molecule has a marked effect on viral replication in CSFV-infected pigs. Here, the effect of antiviral treatment on virus transmission to untreated sentinel pigs was studied. Therefore, BPIP-treated pigs $(n=4)$, intramuscularly infected with CSFV, were placed into contact with untreated sentinel pigs $(n=4)$. Efficient transmission of CSFV from four untreated seeder pigs to four untreated sentinels was observed. In contrast, only two out of four sentinel animals in contact with BPIP-treated seeder animals developed a short transient infection, of which one was likely the result of sentinel to sentinel transmission. A significant lower viral genome load was measured in tonsils of sentinels in contact with BPIP treated seeder animals compared to the positive control group $(\mathrm{p}=0.015)$. Although no significant difference $(p=0.126)$ in the time of onset of viraemia could be detected between the groups of contact animals, a tendency towards the reduction of virus transmission was observed. Since sentinel animals were left untreated in this exploratory trial, the study can be regarded as a worst case scenario and gives therefore an underestimation of the potential efficacy of the activity of BPIP on virus transmission. 


\section{$\underline{\text { Body text }}$}

Classical swine fever (CSFV), Bovine viral diarrhea virus (BVDV) and Border disease virus (BDV) belong to the family of Flaviviridae, genus pestivirus (van Regenmortel et al., 2000) and can, in case of an outbreak, result in major economical consequences for the affected region (Domenech et al., 2006). In particular CSFV has been responsible for major economic losses (Greiser-Wilke et al., 2007). Currently, CSF outbreaks are controlled by a stamping-out policy and pre-emptive eradication of neighbouring herds. These measures proved efficient, but the slaughter of large numbers of often healthy, uninfected pigs is increasingly criticized by the public opinion (van Oirschot, 2003; Le Potier et al., 2006).

As an alternative/additional control strategy, the use of an antiviral treatment for the containment of outbreaks of infectious diseases of livestock like foot-and-mouth disease and CSF has been proposed (Goris et al., 2008; Vrancken et al., 2008). For CSFV, we previously reported on the in vitro inhibition of viral replication by BPIP, a representative of a new class of imidazopyridines, specifically targeting the viral RNA-dependent RNA-polymerase (Vrancken et al., 2008). Subsequent in vivo studies revealed that BPIP was able to significantly reduce the viral load in CSF-infected pigs (Vrancken et al., 2009). It was the purpose of this study to assess the effect of BPIP treatment on the transmission of CSFV from infected pigs to untreated, naive pigs.

An animal experiment was designed, according to the French legislation on animal experimentation, and carried out at the high containment facilities at the Agence Française de Sécurité Sanitaire des Aliments (AFSSA Ploufragan, France). Groups of four, twenty nine-week old, Specific Pathogen Free (SPF) Large White pigs (ca. 30 $\mathrm{kg}$ ) of mixed sex, originating from protected breeding facilities at AFSSA Ploufragan, were held in isolation units. One group of four SPF pigs received BPIP containing 
feed at $75 \mathrm{mg} / \mathrm{kg} /$ day for a period of 15 consecutive days. BPIP synthesis and formulation was carried out as described earlier (Puerstinger et al., 2006; Vrancken et al., 2009). A positive and negative control group was held in a separate isolation unit and received normal feed. One day after the first administration of BPIP, the animals of the BPIP-treated and positive control group were infected intramuscularly with 4 $\mathrm{ml}$ of $10^{4.5} \mathrm{TCID}_{50} / \mathrm{ml}$ of the CSFV field-isolate Wingene (subgroup 2.3, Vanderhallen et al., 1999). Two days post infection (dpi) four untreated sentinel animals were placed in an adjacent pen allowing nose to nose contact between infected and sentinel pigs.

All experimentally infected animals (BPIP-treated and untreated seeder pigs) were clinically observed on a daily basis until 33 dpi and all sentinel animals until 40 dpi. During this observation period all animals were blood sampled three (0-18 dpi) or two (19- 40 dpi) times a week. After the observation period, all animals were euthanized and tonsils were sampled. All blood and organ samples were analyzed by means of virus isolation (VI) and real-time RT-PCR (TaqVet PPC, LSI, France) as described earlier (Vrancken et al., 2009). The real-time RT-PCR assay, using $\beta$-actin as an internal control, had a limit of detection of $2.2 \pm 1.2$ equivalent genome copies (EGC). Samples with a positive signal but a viral load below 2.2 EGC for a $5 \mu 1$ reaction were considered as not quantifiable.

As presented in Fig. 1A, BPIP-treatment had a marked effect on the period of viraemia; three out of four BPIP-treated seeder pigs developed a short transient vireamia of which two animals were only positive for 2 days and one animal for 7 days. The remaining animal tested negative in VI during the whole period of observation. In contrast, the untreated seeder pigs (positive control group) tested invariably positive from 5 dpi until death (22 dpi) or 26 dpi. One animal scored 
positive until the end of the experiment (33 dpi) (Fig. 1B). Analysis of the blood samples of the sentinel pigs in contact with BPIP-treated seeder pigs revealed one positive animal at $14 \mathrm{dpi}$ and a second as late as $26 \mathrm{dpi}$. The two remaining animals remained negative during the whole period of observation (Fig. 1A). All sentinel pigs in contact with the untreated seeder group became viraemic on VI between 14 and 19 dpi. Three out of four animals remained VI positive in blood during the whole period of observation and one contact pig of this group showed a transient infection between 19 and 26 dpi (Fig 1B). The average time until onset of viraemia (VI) in the contact groups was calculated and although a tendency towards later infection could be observed in the sentinel pigs in contact with the BPIP-treated seeder group compared to those in contact with the untreated seeder group $(20.00 \pm 8.49$ days vs. $15.75 \pm 2.36$ days), this difference was not statistically significant $(p=0.126$ [Cox regression survival analysis]).

The effect of a BPIP-treatment on viraemia was substantiated by real time RT-PCR analysis where in the BPIP-treated seeder group one animal with a very low level of CSFV-genome was detected at 2 dpi (EGC not quantifiable). Between day 5 and 16 post experimental inoculation, all BPIP-treated seeder animals scored positive $\left(\log _{10} \mathrm{EGC}\right.$ between $0.55 \pm 0.15$ and $\left.2.52 \pm 0.8\right)$. At $16 \mathrm{dpi}$, three out of four animals tested positive with an average $\log _{10}$ EGC of $0.69 \pm 0.32$. In all four untreated seeder pigs the presence of viral genome was detected throughout the observation period from day 2 post infection until death ( $22 \mathrm{dpi})$ or the end of the experiment ( $33 \mathrm{dpi})$ with $\log _{10}$ EGC between $0.46 \pm 0.28$ and $6.03 \pm 0.98$.

As depicted in Fig. 2, real-time RT-PCR results revealed a significant lower viral genome load in the sentinel group in contact with BPIP-treated seeder pigs than the group in contact with the untreated seeder pigs. In one out of four animals in contact 
with BPIP-treated seeder animals detectable levels of viral RNA were observed from 14 dpi until the end of the study (40 dpi). A second animal became positive between days 26 and 40 post inoculation. As late as 40 dpi, a very low level of viral RNA $\left(\log _{10} \mathrm{EGC}=0.81\right)$ was detected in a third animal and one animal remained negative during the whole observation period. In contrast, the group of sentinel pigs in contact with the untreated seeder pigs, viral RNA could be detected in two out of four animals at $14 \mathrm{dpi}$. A further animal tested positive at $16 \mathrm{dpi}$ and a fourth animal at $19 \mathrm{dpi}$. All animals remained positive until the end of the experiment (40 dpi).

At the end of the experiment, infectious virus could be isolated from the tonsils of one animal in contact with BPIP-treated seeder pigs. Three out of four animals in contact with untreated seeder pigs scored positive in VI (Table 1). Real-time RT-PCR analysis revealed that three out of four pigs in contact with BPIP-treated seeder pigs showed a significantly lower viral genome load in the tonsils compared to the sentinel pigs in contact with the untreated seeder animals $(\mathrm{p}=0.015$ [Two tailed students t-test, unequal variances]) (Table 1).

The VI and real-time RT-PCR results revealed that only one animal developed a short transient infection with an onset comparable to the positive control group (14 dpi), which may be explained by the fact that the BPIP-treated seeder pigs had only a very short period of viraemia. The source of infection of the second VI-positive animal could not be determined in this experimental set-up. A direct infection by contact with the BPIP-treated seeder animals is however unlikely considering the fact that no infectious virus could be isolated from these animals after day 12 pi and that infection of the sentinel could only be demonstrated on VI as late as 26 dpi. Furthermore, because the time interval between the initially infected sentinel pig and the second sentinel pig (12 days), it is reasonable to assume that this infection did not originate 
143 from the seeder pigs, but was most likely due to a secondary transmission from the initially infected contact pig (Ribbens et al., 2004). The same conclusion can likely be drawn for the third animal that, although no infectious virus could be isolated, scored positive on real-time RT-PCR as late as 40 dpi. Although real-time RT-PCR results indicate that a BPIP-treatment resulted in a significant lesser virus transmission towards untreated pigs, it did not result in the observation of a significant later onset of viraemia in the untreated animals in contact with the BPIP-treated seeder group, due to the limited power of the experiment (only 4 contact pigs in each group). Additional experiments must therefore be performed to confirm the here observed tendency towards reduction of virus transmission and to determine the statistical significance.

This exploratory trial can be regarded as a worst-case scenario where both treated and untreated animals were in close contact. Since the aim of an antiviral treatment is not to protect individual animals, but to curb viral spread between herds, all animals within a herd would be treated and therefore the currently obtained results are probably an underestimation of the potential efficacy of an antiviral treatment to reduce virus transmission. Furthermore, both the previously published study of the effect of BPIP on CSFV-viraemia (Vrancken et al., 2009), and the current, were carried out with a lead molecule of this class. Further optimization of the antiviral efficacy could lead to further decrease (if not complete suppression) of the period of viraemia and consequently on virus transmission.

In conclusion, our preliminary findings indicate a reduction of virus transmission from CSFV-infected BPIP-treated animals to untreated sentinel pigs and further trials with BPIP (or a more potent analogue) will be performed to further confirm the observed trend. 


\section{$\underline{\text { Aknowledgements. }}$}

This work was supported by a grant (S6146 section 2) from the research foundation DG4 of the Belgian Government ("Federale Overheidsdienst Volksgezondheid, Veiligheid van de Voedselketen en Leefmilieu") and by the EU Network of Excellence, EPIZONE (Contract No FOOD-CT-2006-016236). J. Paeshuyse is a postdoctoral fellow of the "Fonds voor Wetenschappelijk Onderzoek, Vlaanderen". We thank Cariolet R., Rault J.-C. and Hutet E. for their assistance during the animal trial and Debaugnies R., Denne M., Jebbari F., and Thoraval C. for their technical assistance during this study.

\section{References.}

Domenech, J., Lubroth, J., Eddi, C., Martin, V., Roger, F., 2006, Regional and international approaches on prevention and control of animal transboundary and emerging diseases. Ann N Y Acad Sci 1081, 90-107.

Goris, N., Vandenbussche, F., De Clercq, K., 2008, Potential of antiviral therapy and prophylaxis for controlling RNA viral infections of livestock. Antiviral Res 78, 170178.

Greiser-Wilke, I., Blome, S., Moennig, V., 2007, Diagnostic methods for detection of Classical swine fever virus--status quo and new developments. Vaccine 25, 55245530.

Le Potier, M. F., Mesplede, A., Vannier, P., 2006, Classical swine fever and other pestiviruses. In Diseases of swine, 9 edn, pp. 309-323. Edited by T. D.J.: Blackwell publishing. 
Puerstinger, G., Paeshuyse, J., Herdewijn, P., Rozenski, J., De Clercq, E., Neyts, J., 2006, Substituted 5-benzyl-2-phenyl-5H-imidazo[4,5-c]pyridines: a new class of pestivirus inhibitors. Bioorg Med Chem Lett 16, 5345-5349.

Ribbens, S., Dewulf, J., Koenen, F., Laevens, H., Mintiens, K., de Kruif, A., 2004, An experimental infection (II) to investigate the importance of indirect classical swine fever virus transmission by excretions and secretions of infected weaner pigs. J Vet Med B Infect Dis Vet Public Health 51, 438-442.

van Oirschot, J.T., 2003, Vaccinology of classical swine fever: from lab to field. Vet Microbiol 96, 367-384.

van Regenmortel, M.H.V., Fauquet, C.M., Bishop, D.H.L., Carstens, E.B., Estes, M.K., Lemon, S.M., Maniloff, J., Mayo, M.A., McGeoch, D.J., Pringle, C.R., Wickner, R.B., 2000, Virus Taxonomy: The Seventh Report of the International Committee on Taxonomy of Viruses, In: Academic Press, San Diego, CA, p. 1024. Vanderhallen, H., Mittelholzer, C., Hofmann, M.A., Koenen, F., 1999, Classical swine fever virus is genetically stable in vitro and in vivo. Arch Virol 144, 16691677.

Vrancken, R., Paeshuyse, J., Haegeman, A., Puerstinger, G., Froeyen, M., Herdewijn, P., Kerkhofs, P., Neyts, J., Koenen, F., 2008, Imidazo[4,5-c]pyridines inhibit the in vitro replication of the classical swine fever virus and target the viral polymerase. Antiviral Res 77, 114-119.

Vrancken, R., Haegeman, A., Paeshuyse, J., Puerstinger, G., Rozenski, J., Wright, M., Tignon, M., Le Potier, M.F., Neyts, J., Koenen, F. 2009, A proof of concept for the reduction of classical swine fever infection in pigs by a novel viral polymerase inhibitor. J. Gen. Virol 90, 1335-1342. 
218 Table 1. Virus Isolation (VI) and real-time RT-PCR (expressed as $\log _{10}(\mathrm{EGC})$ ) results

219 of tonsils of untreated sentinel pigs in contact with BPIP-treated (S1 $\rightarrow$ S4) and 220 untreated (PS1 $\rightarrow$ PS4) animals.

\begin{tabular}{ccc}
\hline Animal & VI & $\log _{10}(\mathrm{EGC})$ \\
\hline S1 & + & 3.89 \\
S2 & - & 3.89 \\
S3 & - & neg \\
S4 & - & 3.89 \\
\hline Average: & & 3.89 \\
\hline PS1 & + & 7.66 \\
PS2 & - & 5.26 \\
PS3 & + & 7.31 \\
PS4 & + & 6.29 \\
\hline Average: & & $6.63 \pm 1.08$ \\
\hline
\end{tabular}

222 Viral genome loads of animals in contact with BPIP-treated pigs are significant lower

223 compared to animals in contact with the positive control group $(\mathrm{p}=0.015)$. 


\section{$226 \quad$ Legends to the figures}

227 Fig. 1. Duration of viraemia in blood after infection with CSFV Wingene and 228 transmission to untreated sentinel pigs from A) BPIP-treated/Infected $(1 \rightarrow 4)$ to 229 untreated sentinel $(\mathrm{S} 1 \rightarrow \mathrm{S} 4)$ animals; B) Untreated/Infected $(\mathrm{P} 1 \rightarrow \mathrm{P} 4)$ to untreated 230 sentinel (PS1 $\rightarrow$ PS4) animals. \&: animal euthanized at 22 days post infection; BPIP231 treated and untreated seeder animals were euthanized at 33 days post infection, 232 contact sentinel pigs at 40 days post infection

Fig. 2. Mean virus genome load in blood of untreated sentinel animals in contact with 235 BPIP-treated (diamonds; $\mathrm{n}=4$ ) and untreated (squares; $\mathrm{n}=4$ ) seeder pigs as determined by means of real-time RT-PCR. Number of animals tested positive at a given time point is shown between brackets. Statistical significance (p-values) is given at each measureable timepoint. 
Virus Isolation in Blood

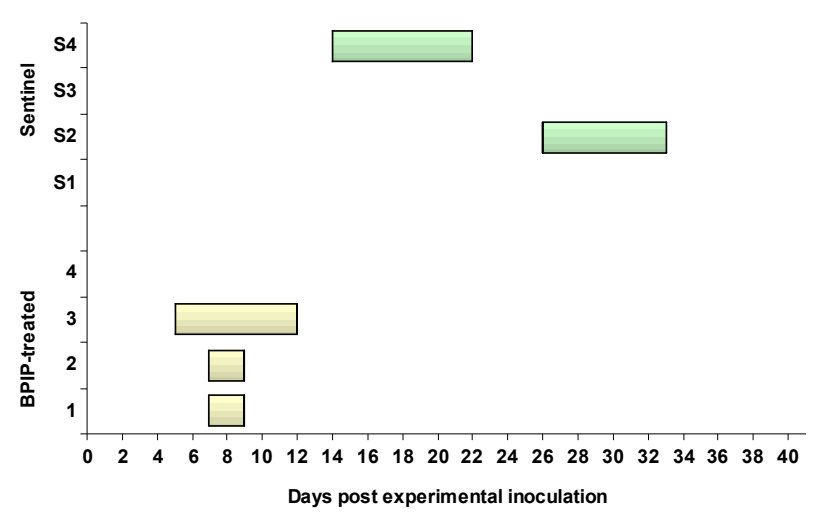

Virus Isolation in Blood

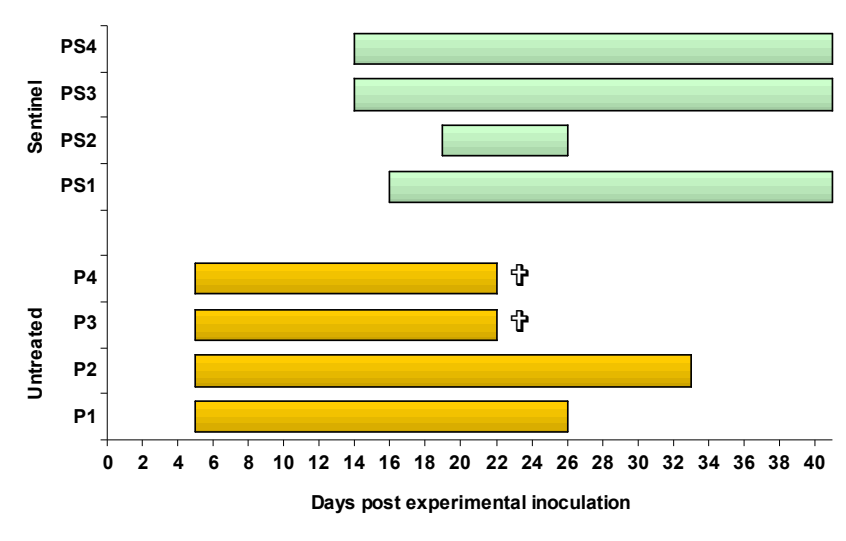




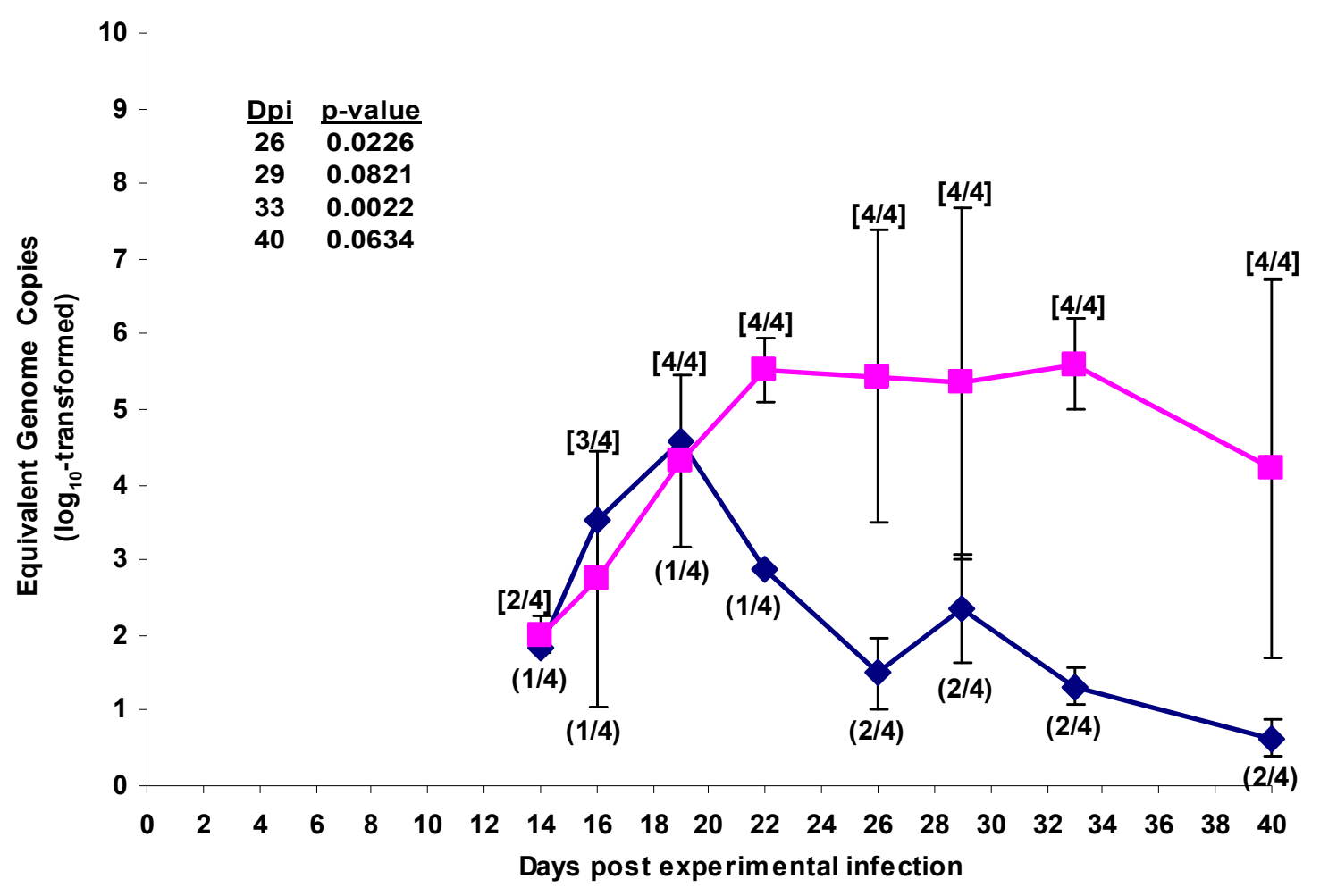

